Open Access

\title{
Changes in hormone flux and signaling in white spruce (Picea glauca) seeds during the transition from dormancy to germination in response to temperature cues
}

Yang Liu' ${ }^{1}$, Kerstin Müller ${ }^{2}$, Yousry A. El-Kassaby ${ }^{1}$ (1) and Allison R. Kermode $2^{2^{*}}$

\begin{abstract}
Background: Seeds use environmental cues such as temperature to coordinate the timing of their germination, allowing plants to synchronize their life history with the seasons. Winter chilling is of central importance to alleviate seed dormancy, but very little is known of how chilling responses are regulated in conifer seeds. White spruce (Picea glauca) is an important conifer species of boreal forests in the North American taiga. The recent sequencing and assembly of the white spruce genome allows for comparative gene expression studies toward elucidating the molecular mechanisms governing dormancy alleviation by moist chilling. Here we focused on hormone metabolite profiling and analyses of genes encoding components of hormone signal transduction pathways, to elucidate changes during dormancy alleviation and to help address how germination cues such as temperature and light trigger radicle emergence.

Results: $A B A, G A$, and auxin underwent considerable changes as seeds underwent moist chilling and during subsequent germination; likewise, transcripts encoding hormone-signaling components (e.g. ABI3, ARF4 and Aux/IAA) were differentially regulated during these critical stages. During moist chilling, active IAA was maintained at constant levels, but IAA conjugates (IAA-Asp and IAA-Glu) were substantially accumulated. $A B A$ concentrations decreased during germination of previously moist-chilled seeds, while the precursor of bioactive GA1 (GA53) accumulated. We contend that seed dormancy and germination may be partly mediated through the changing hormone concentrations and a modulation of interactions between central auxin-signaling pathway components (TIR1/AFB, Aux/IAA and ARF4). In response to germination cues, namely exposure to light and to increased temperature: the transfer of seeds from moist-chilling to $30^{\circ} \mathrm{C}$, significant changes in gene transcripts and protein expression occurred during the first six hours, substantiating a very swift reaction to germination-promoting conditions after seeds had received sufficient exposure to the chilling stimulus.

Conclusions: The dormancy to germination transition in white spruce seeds was correlated with changes in auxin conjugation, auxin signaling components, and potential interactions between auxin-ABA signaling cascades (e.g. the transcription factor ARF4 and ABI3). Auxin flux adds a new dimension to the ABA:GA balance mechanism that underlies both dormancy alleviation by chilling, and subsequent radicle emergence to complete germination by warm temperature and light stimuli.
\end{abstract}

Keywords: Seed dormancy, Auxin, ABA, GAs, Moist-chilling, Seed germination, White spruce

\footnotetext{
* Correspondence: kermode@sfu.ca

${ }^{2}$ Department of Biological Sciences, Simon Fraser University, Burnaby, British

Columbia V5A 156, Canada

Full list of author information is available at the end of the article
}

C Biomed Central

(c) 2015 Liu et al. Open Access This article is distributed under the terms of the Creative Commons Attribution 4.0 International License (http://creativecommons.org/licenses/by/4.0/), which permits unrestricted use, distribution, and reproduction in any medium, provided you give appropriate credit to the original author(s) and the source, provide a link to the Creative Commons license, and indicate if changes were made. The Creative Commons Public Domain Dedication waiver (http://creativecommons.org/publicdomain/zero/1.0/) applies to the data made available in this article, unless otherwise stated. 


\section{Background}

Conifers are ecologically and economically important plants, and coniferous forests cover vast tracts in the Northern hemisphere. White spruce (Picea glauca) is a keystone species of boreal forests in the North American taiga. In Canada, over 100 million white spruce seedlings are out-planted yearly for regeneration [1]. However, our understanding of molecular mechanisms underlying the dormancy and germination of white spruce seeds and of conifers in general remains quite limited. As the white spruce genome was the first to be sequenced and assembled amongst conifer species in 2013, interest in investigating aspects of the molecular mechanisms underlying key developmental and physiological processes is mounting [2-4].

Moist-chilling is a common dormancy-breaking stimulus for conifer seeds both in natural stands and under laboratory conditions. Specific requirements can vary enormously amongst different conifer species, as well as amongst different clones and seed lots of a given species $[5,6]$; for white spruce, the typical moist-chilling requirement under laboratory conditions is approximately 21 days.

During seed maturation, exposure of seeds on the parent plant to low temperatures can influence the depth of primary dormancy of the mature seeds. In the imbibed mature dormant seed, dormancy alleviation is often promoted by exposure to chilling. It is therefore assumed that chilling plays a dual role in regulating dormancy [7]. In addition, under some conditions, extended chilling can result in secondary dormancy $[8,9]$. Mechanisms that underlie the beneficial effects of moist-chilling on dormancy alleviation undoubtedly involve plant hormones - with abscisic acid (ABA) and gibberellins (GAs) receiving the most attention, alone and within the context of their interplay or crosstalk with other hormones such as auxins, cytokinins, and ethylene [10-14].

Although evolutionarily independent from the other seed-bearing plants since 260 million years ago [15], the seeds of conifers exhibit conserved mechanisms regulating their dormancy and germination with seeds of angiosperms, including those mediated by ABA [16-18]. Several studies demonstrate that moist-chilling invokes changes in the levels of, and sensitivity to, ABA and GAs in conifer seeds [19-21]. ABA levels are reduced during moist-chilling-induced dormancy termination of yellowcypress (Callitropsis nootkatensis) and Douglas-fir (Pseudotsuga menziesii) seeds [22, 23]. ABA levels of western white pine (Pinus monticola) seeds also decline significantly during moist-chilling, and this decline is associated with an increase in germination capacity [24]. It is noteworthy that if dormancy-breaking conditions are not met, seeds maintain high ABA levels; and dormancy imposition and maintenance require $\mathrm{ABA}$ biosynthesis
[25]. For western white pine seeds, it is the ratio of ABA biosynthesis to catabolism that appears to be the key factor that determines the capacity for dormancy maintenance versus germination. GAs have a positive effect on dormancy alleviation and germination of conifer seeds [25]; likewise, dormancy alleviation of moistchilled Arabidopsis seeds depends on the expression of $\mathrm{GA}_{3}$ oxidase 1 of the GA biosynthesis pathway $[19,21]$. In hazel (Corylus avellana), moist-chilling has a pronounced effect on the capacity of the seeds for GA biosynthesis, although active GA production does not take place until the seeds are placed in germination conditions [26].

In the ABA signalling cascade of Arabidopsis, concerted actions of four transcription factors, i.e. ABSCISIC ACID INSENSITIVE 3 (ABI3), FUSCA 3 (FUS3), LEAFY COTYLEDON 1 (LEC1), and LEAFY COTYLEDON 2 (LEC2), mediate various seed maturation processes and some of these factors also participate in the transition from dormancy to germination [27, 28]. Orthologs of $A B I 3$, encoding a structurally conserved transcription factor have been isolated from angiosperm and gymnosperm (conifer) species, and they act as central regulators of seed development and dormancy [10, 29]. A member of the $A B I 3 / V P 1$ family cloned from yellow-cypress is positively associated with dormancy maintenance [30]. Through yeast two-hybrid analyses, a yellow-cypress ABI3 Interacting protein (CnAIP2) that functions as a negative regulator of ABI3 was recently identified [31]; note that this protein is different from the Arabidopsis E3 ubiquitin ligase, AIP2 [32]. CnAIP2, like CnABI3, acts a central gatekeeper of important plant life cycle transitions including the seed dormancy-to-germination transition [31].

GAs also modulate plant growth and development and can act antagonistically to ABA in the control of both seed dormancy and germination [11,33]. Notably, regulation of seed germination via light and temperature is correlated with GA metabolism and signalling in many species [10, 19, 27, 34]. Exogenous application of GAs to western white pine seeds initiates a decrease in ABA levels in dormant seeds by changing $A B A$ homeostasis, i.e. promoting $\mathrm{ABA}$ catabolism or transport over $\mathrm{ABA}$ biosynthesis [25].

The hormone auxin (principally indole-3-acetic acid [IAA]) regulates many aspects of plant growth and development. Amide-linked conjugates of IAA synthesized during seed development $[35,36]$ can serve as a source of free IAA during seed germination [37, 38]. Several lines of evidence implicate a role for auxins in seed dormancy maintenance in Arabidopsis [39-41]; auxinmediated seed dormancy maintenance depends on ABI3 and this inhibitory effect can be nullified by moistchilling [42]. The hub of the auxin signalling pathway is the TRANSPORT INHIBITOR RESPONSE1 (TIR1)/ 
AUXIN SIGNALING F-BOX (AFB) proteins signaling system [43-45].

In this work, we studied one white spruce (Picea glauca) population from British Columbia, Canada, to elucidate the hormone-based mechanisms that underpin dormancy alleviation and germination in response to temperature signalling (i.e. moist chilling and transfer to germination conditions). This research will help provide insights into how winter chilling contributes to the timing of phenology, and how conifer life histories may develop under new climate scenarios.

\section{Methods}

Seed materials, germination testing, and seed sampling One white spruce population from British Columbia, Canada (located at $54^{\circ} 26^{\prime} \mathrm{N}, 121^{\circ} 44^{\prime} \mathrm{W}, 850 \mathrm{~m}$ elevation), was selected for this study based on cumulative germination performance after the standard 21-day moistchilling treatment [46]. For germination characterization, seeds were first moist-chilled in clear plastic germination boxes (Hoffman) lined with moistened cellulose wadding and filter paper, and moistened with $50 \mathrm{~mL}$ of sterile water for 21 days at $3{ }^{\circ} \mathrm{C}$ in a dark environment. The boxes containing seeds were then transferred into germination conditions $\left(30 / 20{ }^{\circ} \mathrm{C}\right.$, 8-h-photoperiod and $70 \%$ relative humidity). Light was provided by fluorescence illumination at approximately $13.5 \mu \mathrm{mol} \cdot \mathrm{m}^{-2} \mathrm{~s}^{-1}$. Standard germination was conducted over a 21-day span following the International Seed Testing Association standards [47]. As controls for the transfer to the germination-promoting conditions $\left(30 / 20{ }^{\circ} \mathrm{C}\right.$ and light), seeds were transferred to constant darkness at $30 / 20{ }^{\circ} \mathrm{C}$, or were kept in moist-chilling conditions (constant $3{ }^{\circ} \mathrm{C}$ ) with an 8-h photoperiod. Germination assays, scoring, and quantification were performed as previously described [46].

Seed sampling for molecular and biochemical analyses was conducted on 3 biological replicates and included times during moist-chilling $(0,10$ and $21 \mathrm{~d})$ and after transfer to germination or control conditions $(6,24,80 \mathrm{~h}$, and $9 \mathrm{~d})$ (Fig. 1a). For seeds that had been maintained in darkness, the sampling was also conducted in darkness. Samples comprising the 3 replicates were collected and immediately frozen in liquid $\mathrm{N}_{2}$ and stored at $-80{ }^{\circ} \mathrm{C}$.

\section{Reference gene selection and gene query using BLASTN}

Three genes were chosen and used as internal controls: CO220221 (peroxisomal targeting signal receptor), CO206996 (hypothetical protein), and AY639585 (ubiquitin conjugating enzyme $1, \mathrm{UBC} 1$ ); these were selected due to their constitutive expression during developmental transitions as determined by published microarray profiling $[48,49]$. A subset of genes specifying proteins mediating the committed steps of ABA, GA and auxin biosynthesis/catabolism or signalling pathways (Fig. 2), were used to query the spruce EST database (PlantGDB) and the white spruce whole genome data (NCBI) using BLASTN. Primers (Additional file 1: Table S1) were designed with the primer3 tool online [50].

\section{RNA isolation, quantitative (q)RT-PCR and principle component analysis}

RNA was isolated from seeds as previously outlined [51]. Two $\mu \mathrm{g}$ of RNA was reverse-transcribed into cDNA using the EasyScript Plus ${ }^{\mathrm{ma}}$ kit (abmGood) with oligo-dT primers. First-strand cDNA synthesis products were diluted fivefold, and one $\mu$ of cDNA was used to carry out semi-quantitative RT-PCR for a primer specificity check. Quantitative RT-PCR (qRT-PCR) analyses were run with three biological replicates per sample in $15-\mu \mathrm{l}$ reaction volumes in an ABI7900HT machine (Applied Biosystems) using the PerfeCTa ${ }^{\circ} \mathrm{SYBR}^{\circ}$ Green SuperMix with ROX (Quanta Biosciences). The reaction mixture consisted of $1.0 \mu$ l fivefold diluted cDNA, $7.5 \mu$ l supermix and $1.0 \mu \mathrm{l}$ of each primer $\left(10 \mu \mathrm{mol} \cdot \mathrm{L}^{-1}\right)$. The reaction procedure was $5 \mathrm{~min}$ at $95{ }^{\circ} \mathrm{C}, 45$ cycles of $15 \mathrm{~s}$ at $95{ }^{\circ} \mathrm{C}$ and $60 \mathrm{~s}$ at $59^{\circ} \mathrm{C}$. Dissociation curves were generated at the end of each qRT-PCR to validate the amplification of only one product. Efficiency calculation and normalization were performed using real-time PCR Miner (www.miner.ewindup.info/) [52] and data quality was confirmed through internal controls and no-templatecontrols, and by comparing the repeatability across replicates. An average expression value for each gene at each time point was generated from the normalized data.

Principle component analysis (PCA) was performed using SAS $^{\circ}$ (vers. 9.3; SAS Institute Inc., Cary, NC) based on the expression patterns of all genes in different germination conditions at 6,24 , and $80 \mathrm{~h}$ as described in the text.

\section{Western blot analysis}

Protein extracts were generated by grinding the seed materials in protein extraction buffer $(50 \mathrm{mM}$ Tris $\mathrm{pH} 8.0$, $150 \mathrm{mM} \mathrm{NaCl}, 1 \%$ Triton X-100, and $100 \mu \mathrm{g} \cdot \mathrm{ml}^{-1}$ phenylmethylsulfonyl fluoride) and protein concentration was determined by measuring $\mathrm{OD}_{750}$ with the aid of photometer. Protein extracts (30 $\mu \mathrm{g}$ total soluble protein) were separated by $10 \%$ SDS-PAGE and transferred onto Amersham Hybond-P (PVDF) membranes using wet electroblotting. The blots were blocked overnight at $3{ }^{\circ} \mathrm{C}$ using $5 \%(\mathrm{w} / \mathrm{v})$ non-fat dry milk and $0.1 \%(\mathrm{v} / \mathrm{v})$ Tween-20 (PBST) followed by three washes (15 min each) with PBST. Blots were incubated with the anti-pgKS (ent-kaurene synthase) antibody (1:500 dilution) for $1 \mathrm{~h}$ at room temperature (provided by T-P. Sun's lab). After three washes with PBST (15 min each) the membrane was 
a
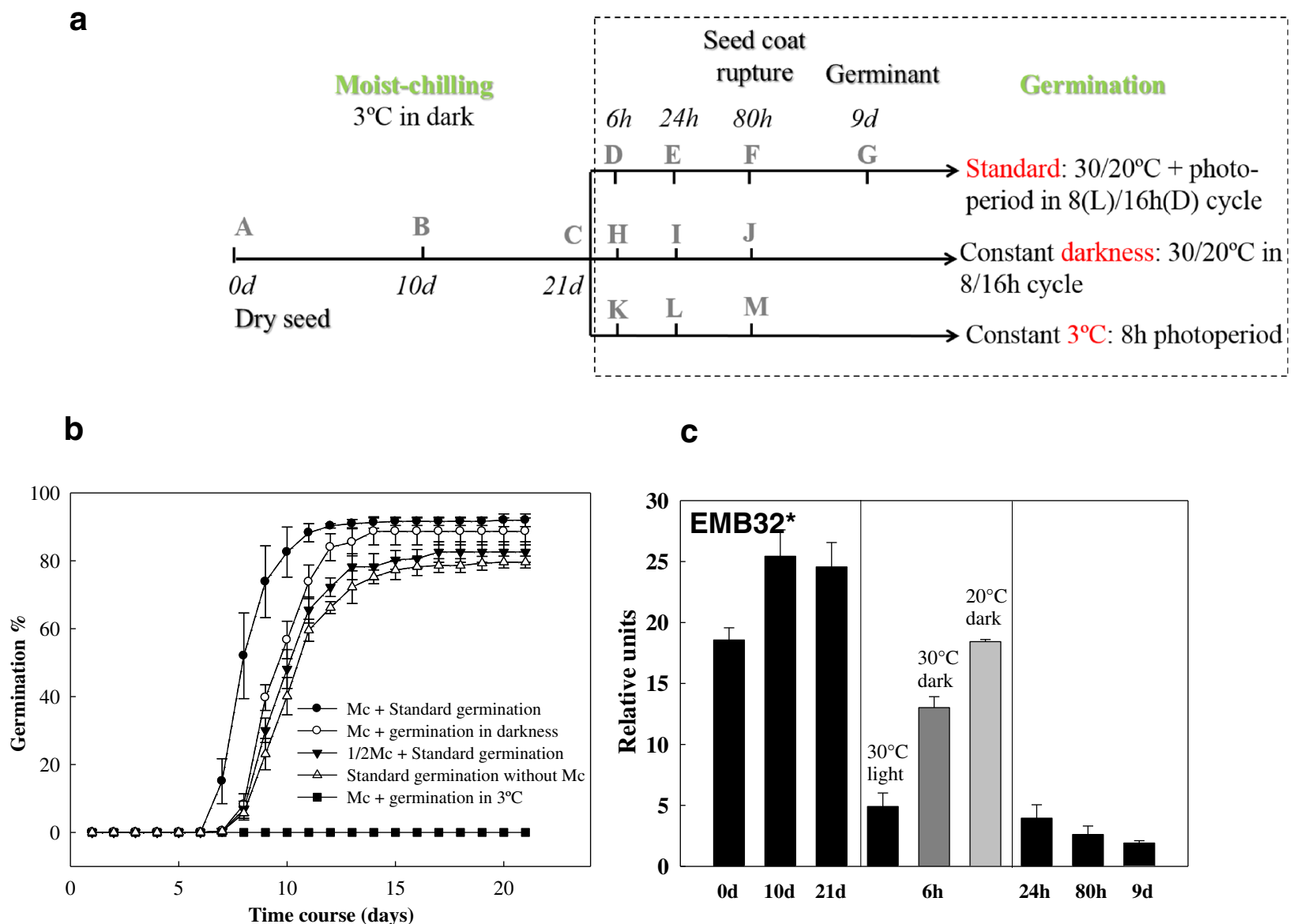

Fig. 1 Effect of moist chilling on the germination performance of white spruce seeds. a Schematic representation of sampling to determine germination of white spruce seeds in different germination conditions with a 21-d or 10-d moist-chilling period (Mc or 1/2Mc) or no moist chilling. In standard germination conditions $\left(30 / 20^{\circ} \mathrm{C}\right.$ and an 8 -h photoperiod), seed coat rupture and radicle protrusion was observed at $80 \mathrm{~h}$ in the majority of the population. The stage at which the radicle had emerged to four times of the seed length was reached on $d$ 9. $\mathbf{b}$ Germination of white spruce seeds under the conditions represented in (a) and without moist chilling. Data points are means \pm SE of four dishes of 100 seeds each. While biologists define the completion of germination as radicle emergence, 'germination' percentage in the forest industry is based on the number of seeds that reach the stage when the radicle has emerged to four times the seed length (approximately $4 \mathrm{~mm}$ for white spruce). In $\mathbf{b}$, we used this latter definition. c Transcript dynamics of the dormancy marker, EMB32 during moist-chilling (0, 10, 21 d), germination $(6,24,80 \mathrm{~h})$ and seedling growth (9 d) (black bars). At the $6 \mathrm{~h}$ time-point, transcript levels were determined under three conditions: in seeds after their transfer to standard germination conditions $\left(30 / 20{ }^{\circ} \mathrm{C}\right.$ and 8 -h photoperiod) (black bar), in seeds maintained in darkness at $30{ }^{\circ} \mathrm{C}$ (dark grey bars), and in seeds maintained in darkness at $20^{\circ} \mathrm{C}$ (light grey bars). Relative expression levels as determined by RT-qPCR are shown. Each data point is the average of three biological replicates. Bars indicate the SEM. Note: one asterisk $\left(^{*}\right)$ indicates that the gene has been annotated in gymnosperms but not in white spruce

incubated with the anti-rat HRP (horseradish peroxidase) antibody (1:40,000 dilution) for $1 \mathrm{~h}$ at room temperature. After three washes with PBST (15 min each) the membrane was drained and placed within wrap film containing $2 \mathrm{ml}$ Supersignal West Pico solution and the membrane exposed to light. Chemiluminescent images were captured by a CCD camera system (Fujifilm LAS 4000).

\section{Plant hormone quantification by HPLC-ESI-MS/MS}

Methods for quantification of multiple hormones and metabolites, including $\mathrm{ABA}$ and its metabolites (cisABA, trans-ABA, ABA-GE, PA, DPA, 7'OH-ABA, and
neoPA), gibberellins $\left(\mathrm{GA}_{53}\right.$ and $\mathrm{GA}_{34}$ ), auxins/auxin conjugates (IAA, IAA-Asp, and IAA-Glu), and cytokinins (iPR, cis-ZR, and cis-ZOG) followed those previously described [53, 54].

Briefly, lyophilized seed samples were ground and a mixture of all internal standards was added to duplicate homogenized seed samples ( $\sim 50 \mathrm{mg}$ each), and extraction performed using acidic isopropanol. Samples were reconstituted and purified by solid phase extraction (SPE) with Sep-Pac C18 cartridges (Waters, Mississauga, ON, Canada). Subsequently, samples were injected onto an ACQUITY UPLC HSS C18 SB column $(2.1 \times$ 


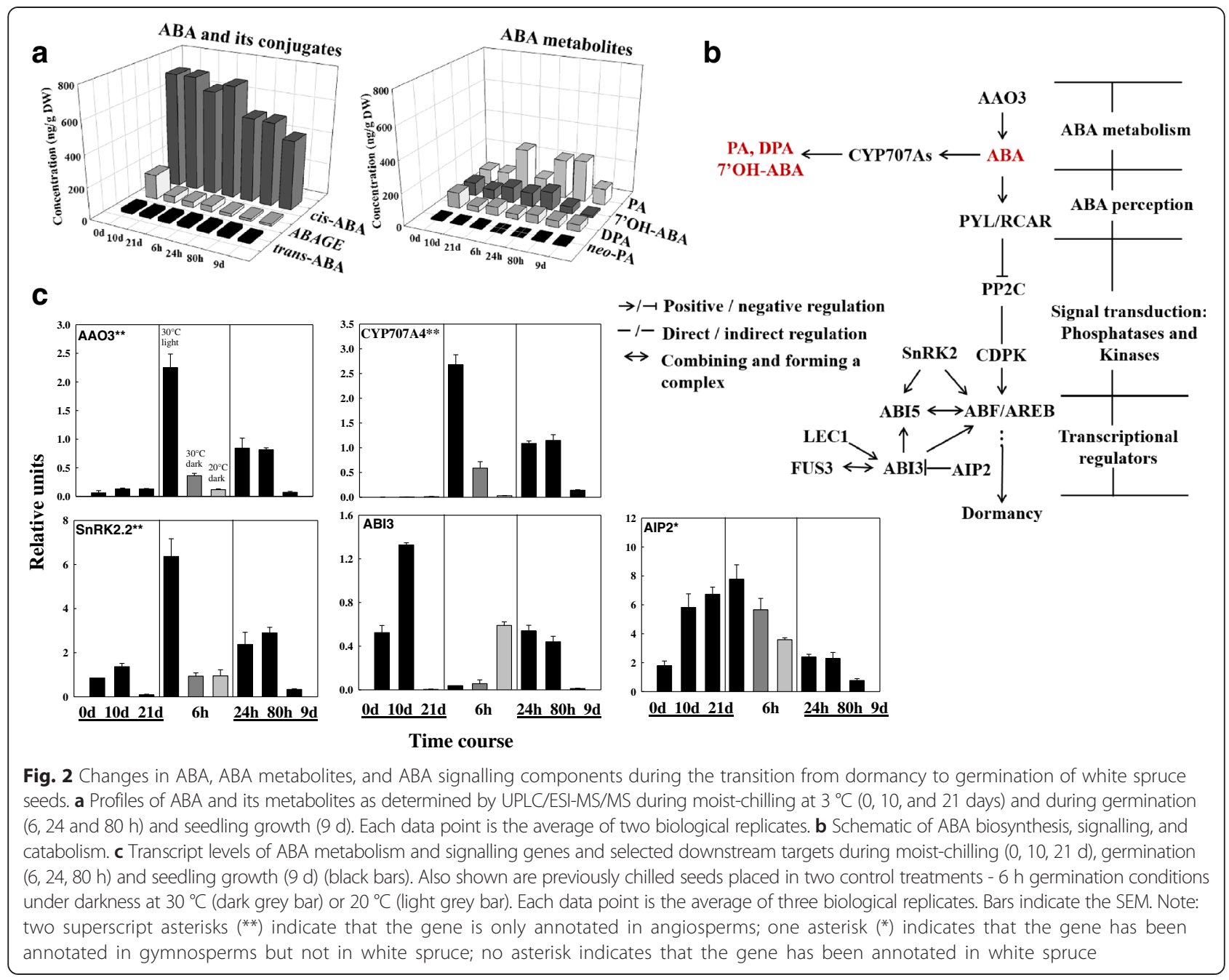

$100 \mathrm{~mm}, 1.8 \mu \mathrm{l})$ with an in-line filter and separated by a gradient elution of water containing $0.02 \%$ formic acid against an increasing percentage of a mixture of acetonitrile and methanol (50:50, v/v). The analysis utilized the Multiple Reaction Monitoring function of the MassLynx v4.1 (Waters Inc) control software. The quality control samples and internal standard and solvent negative controls were prepared and analyzed along with samples.

\section{Results}

\section{Germination profiles of white spruce seeds under different germination conditions}

The mature seeds of white spruce have a relatively shallow dormancy level, and can germinate even without moist chilling. However, exposure of seeds to moist chilling led to faster and more uniform germination (Fig. 1b).

To investigate the effect of light on dormancy alleviation and germination, white spruce seeds were placed under different conditions following exposure to 21 days of moist chilling. The fastest and most homogenous germination occurred when seeds were subjected to light (an 8 -h photoperiod) and a $30 / 20^{\circ} \mathrm{C}$ temperature regime (standard germination conditions), compared to when they were kept in darkness (Fig. 1b). After the 21-day moist-chilling, subsequent seed germination under the combined conditions of $30 / 20{ }^{\circ} \mathrm{C}$ and an 8-h photoperiod was more successful than in constant darkness but with the same $30 / 20{ }^{\circ} \mathrm{C}$ temperature cycle. This was the case based on most germination parameters: dormancy index (i.e., area between germination curves of no- treatment and any treatment; $15.54 \pm 2.12$ vs. $7.56 \pm$ 0.97), germination speed (i.e. the time required for $50 \%$ germination, $8 \mathrm{~d}$ vs. $10 \mathrm{~d}$ ), and lag time to germination (6 d vs. 7 d) (Fig. 1b). Germination capacities were similar for the two treatments at the end of the 21-day study period (96 \% vs. $94 \%$ ) (Fig. 1b). Seeds subjected to a control treatment - maintaining them at $3{ }^{\circ} \mathrm{C}$, but exposing them to an 8-h photoperiod - were unable to germinate (Fig. 1b). Regardless of the light conditions after transfer to germination temperatures (8-h photoperiod or 
constant darkness), germination of the population of seeds that had been subjected to moist chilling was faster and more synchronous than for the populations of seeds that had not received moist-chilling; and 21-day chilling was more beneficial than the 10-day chilling treatment (Fig. 1b). This indicates that moist-chilling has a significant effect on dormancy alleviation, and that light cues following exposure of seeds to germination temperatures facilitate germination.

\section{Expression of the gene EMB32, encoding a Late Embryogenesis Abundant (LEA) protein}

Dormancy status was also investigated by monitoring the expression of the ABA-regulated gene EMB32, a member of the Late Embryogenesis Abundant (LEA) group. Dormancy maintenance bears some similarities to the late maturation program [55], and EMB32 and the other LEAs have a role in ensuring seed survival in the desiccated/dormant state. As such, EMB32 can be used as a dormancy marker [56]. Indeed, during moistchilling of white spruce seeds, the expression of this $L E A$ gene was maintained at a high level, but this expression decreased very quickly when seeds were transferred to germination conditions, even as soon as six hours under standard germination conditions (Fig. 1c, $30{ }^{\circ} \mathrm{C}$ ). Thus, the dormancy to germination transition began promptly when the seeds were exposed to light upon transfer to germination temperatures.

\section{Dynamic changes in plant hormone pathways in response to temperature cues during moist-chilling and seed germination}

To investigate hormone metabolism and signalling during dormancy alleviation and germination, hormone levels and transcription of genes specifying the protein mediators of hormone metabolism and signalling were determined at the various sampling stages (Fig. 1a).

\section{$A B A$ metabolism and signalling}

Biologically active cis-S(+)-ABA did not substantially change in abundance during moist-chilling itself, but decreased during subsequent germination of previously chilled white spruce seeds (Fig. 2a). The so-called "transABA" is in fact a product of isomerization of natural ABA under UV light, and this did not change during the transition to germination. Generally the bioactive ABA levels were much higher than those of the ABA catabolites. From the changes in ABA metabolites it was apparent that the main $\mathrm{ABA}$ metabolism pathway in white spruce seeds is through 8'-hydroxylation (resulting in phaseic acid (PA), which is further reduced to dihydrophaseic acid (DPA)). Nonetheless, secondary catabolism pathways such as 7' and 9' hydroxylation (resulting in 7'hydroxy ABA and neo-PA) as well as conjugation (resulting in ABA-GE) were also represented. The various catabolites, especially $\mathrm{PA}$ and the 7'OH-ABA increased during moist chilling, as well as during germination of moist-chilled seeds (Fig. 2a).

Transcript abundance of $A B I 3$ was markedly upregulated during the first $10 \mathrm{~d}$ of moist chilling, but declined to a barely detectable level at $21 \mathrm{~d}$ (Fig. 2c). $S n R K 2.2$ transcripts exhibited a similar expression pattern during the moist chilling phase (Fig. 2c). Thus, while absolute ABA levels remained constant, transcription of genes for ABA signalling components, and thereby sensitivity to $A B A$, started to decline during the latter part of the moist chilling phase (Fig. 2b, c). Moreover, transcripts of a putative ortholog of a negative regulator of $\mathrm{ABI} 3, \mathrm{CnAIP2}$ [31], steadily accumulated during moist-chilling and remained high during early germination $(6 \mathrm{~h})$. $A B I 3$ transcripts, were high at the mid-point during moist chilling, then declined precipitously during late moist chilling and early germination, but increased during the later stages of germination (24 and 80 h) (Fig. 2c).

Transcripts encoding AAO3 (ABA biosynthesis enzyme) underwent few changes during moist chilling, but increased dramatically during early germination under standard conditions, followed by a decline; those for CYP707A4 (encoding ABA 8' hydroxylase) were not detectable (Fig. 2c). Similar to $A A O 3$, transcripts encoding CYP707A4 and SnRK2.2 showed a significant upregulation during the early stages when seeds were first transferred to standard germination conditions at $6 \mathrm{~h}$, with transcripts declining at the later stages (Fig. 2c). An actual decline in bioactive ABA was not evident until $24 \mathrm{~h}$ of germination (Fig. 2a). At the seedling stage (9 d), transcripts for all of the monitored genes involved in ABA metabolism and signalling decreased to a very low level (Fig. 2c).

\section{GA metabolism and signalling}

Of the 14 GAs that were quantified in white spruce seeds (i.e., $\mathrm{GA}_{1}, 3,4,7,8,9,19,20,24,29,34,44,51$, and ${ }_{53}$ ), only $\mathrm{GA}_{53}$ and $\mathrm{GA}_{34}$ were present at detectable levels. $\mathrm{GA}_{53}$ is an early precursor in the 13-hydroxylation pathway $\left(\mathrm{GA}_{53} \rightarrow \mathrm{GA}_{44} \rightarrow \mathrm{GA}_{19} \rightarrow \mathrm{GA}_{20}\left(\rightarrow \mathrm{GA}_{29}\right) \rightarrow \mathrm{GA}_{1} \rightarrow\right.$ $\mathrm{GA}_{8}$ ) and leads to the formation of bioactive $\mathrm{GA}_{1}$ and its inactive degradation product $\mathrm{GA}_{8} ; \mathrm{GA}_{34}$ is an inactive catabolite of biologically active $\mathrm{GA}_{4}$ in the nonhydroxylation biosynthetic pathway $\left(\mathrm{GA}_{12} \rightarrow \mathrm{GA}_{15} \rightarrow\right.$ $\left.\mathrm{GA}_{24} \rightarrow \mathrm{GA}_{9}\left(\rightarrow \mathrm{GA}_{51}\right) \rightarrow \mathrm{GA}_{4} \rightarrow \mathrm{GA}_{34}\right)$. The presence of intermediates from both biosynthesis routes suggests that both GA metabolic pathways are active in white spruce seeds during dormancy alleviation and germination. Moreover, the presence of $\mathrm{GA}_{34}$ suggests that $\mathrm{GA}_{4}$ must have been produced at earlier stages. $\mathrm{GA}_{53}$ of the early 13-hydroxylation pathway conducive to 
the formation of bioactive $\mathrm{GA}_{1}$ increased steadily during germination under standard conditions after seeds had received moist chilling. During moist-chilling itself, $\mathrm{GA}_{53}$ and $\mathrm{GA}_{34}$ were maintained at steady-state levels, with $\mathrm{GA}_{53}$ present at $\sim 5$-fold higher levels than
$\mathrm{GA}_{34}$ (Fig. 3a). $\mathrm{GA}_{34}$ increased most substantially at 9 d (i.e. during seedling growth) (Fig. 3a).

Most of the GA-related genes that we monitored (those encoding mediators of GA- biosynthesis, signalling, or action; Fig. 3b) were expressed at low levels

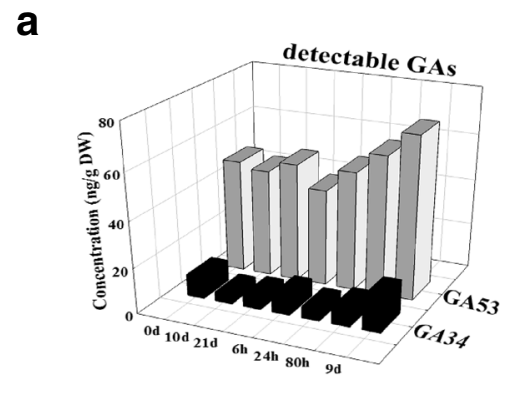

\section{b}

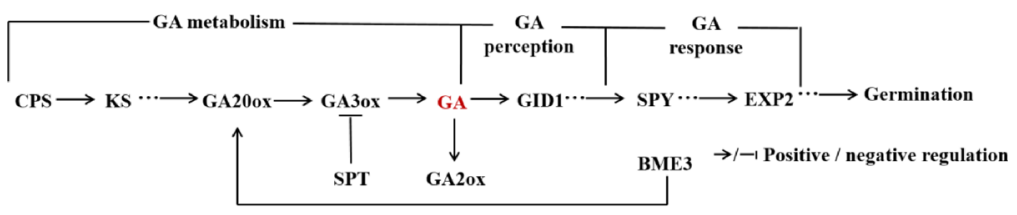

C
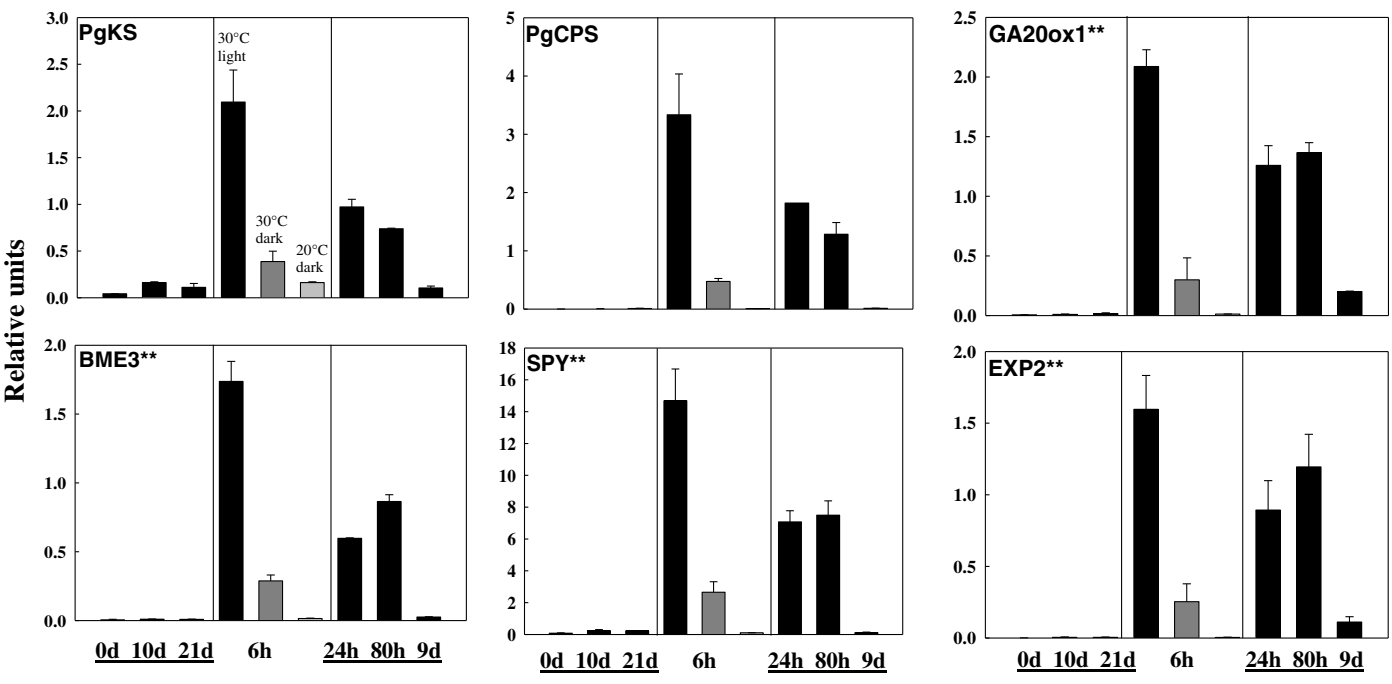

Time course

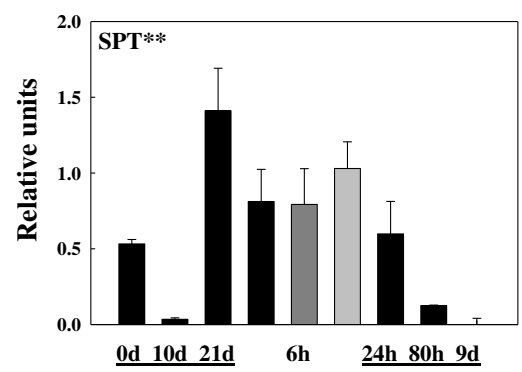

d
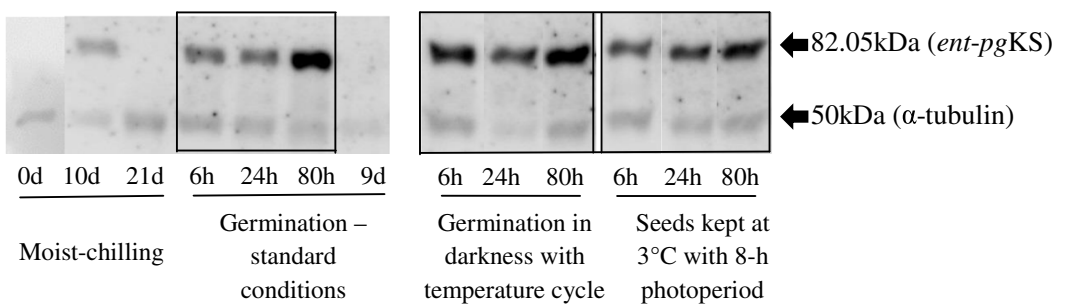

Time course

Fig. 3 Changes in GAs and GA signalling components during the transition from dormancy to germination of white spruce seeds. a Profiles of the GA precursor $\mathrm{GA}_{53}$ and the metabolite $\mathrm{GA}_{34}$ as determined by UPLC/ESI-MS/MS during moist-chilling at $3{ }^{\circ} \mathrm{C}(0,10$, and 21 days), and during germination (6, 24 and $80 \mathrm{~h}$ ) and seedling growth (9 d). Each data point is the average of two biological replicates. No active GAs were detected in our analysis. $\mathbf{b}$ Schematic characterization of key genes and their interplays in GA signaling cascades. Connections represent positive (arrow) and negative (block) regulation. c Transcript levels of GA metabolism genes and selected downstream targets during moist-chilling (0, 10, $21 \mathrm{~d})$, germination $(6,24,80 \mathrm{~h}$ ) and seedling growth (9 d) (black bars). Also shown are previously chilled seeds placed in two control treatments $-6 \mathrm{~h}$ germination conditions under darkness at either $30^{\circ} \mathrm{C}$ (dark grey bar) or $20^{\circ} \mathrm{C}$ (light grey bar). Each data point is the average of three biological replicates. Bars indicate the SEM. Note: see Fig. 2 note for asterisks. $\mathbf{d}$ Ent-pgKS protein levels during moist-chilling, germination, and growth of white spruce seeds. Immunoblots show $30 \mu \mathrm{g}$ of total protein extract per lane. Blots were probed with anti-KS antibody and anti-tubulin as a loading control 
during moist-chilling (Fig. 3c). (Note that all reference genes were expressed during these times; Additional file 1: Figure S3). The expression of SPT (SPATULA), encoding a mediator of ABA- and GA- signaling cross talk, decreased to a low level at $10 \mathrm{~d}$ of moist chilling but exhibited a 14-fold increase at $21 \mathrm{~d}$ (Fig. 3c).

We also investigated transcript abundance of genes known to be positively regulated by GA as indirect indicators of the presence of active GA. The GA-regulated cell wall-modifying gene, expansin 2 (EXP2), exhibited a 15 -fold up-regulation within $6 \mathrm{~h}$ after transfer of moist chilled seeds to standard germination conditions (Fig. 3c). The expression of other GA-related genes was also substantially increased during early germination before radicle protrusion; moderate expression occurred between $24-80 \mathrm{~h}$, while at the seedling stage, the expression of all of the monitored genes was low or virtually undetectable (Fig. 3c). This is indicative of the presence of active GA during completion of germination and during very early seedling growth (seedling emergence).

Ent- $p g$ KS protein levels were increased during the first $10 \mathrm{~d}$ of moist chilling, with a decline during the latter period of moist chilling (Fig. 3d). Upon transfer of moist-chilled seeds to germination conditions, the levels increased by $6 \mathrm{~h}$ (coincident with increased transcript levels; Fig. 3c). The most pronounced ent-pgKS protein levels were evident in seeds at $80 \mathrm{~h}$ under standard germination conditions; however, the control treatments indicated that either changing the light conditions or exposing seeds to germination temperatures were sufficient to trigger the increased levels of this protein (Fig. 3d).

\section{Auxin metabolism and signalling}

Active IAA was almost at constant levels throughout the moist chilling period, and during germination (Fig. 4a). IAA conjugates (IAA-Asp and IAA-Glu) strikingly increased over 20-fold during the $21 \mathrm{~d}$ of moist-chilling (Fig. 4a). These conjugated IAAs declined markedly during the first $6 \mathrm{~h}$ in standard germination conditions; later seedling growth was accompanied by an increase in both active and conjugated IAA (Fig. 4a).

In the auxin pathway (Fig. $4 \mathrm{~b}, \mathrm{c}$ ), the expression of auxin biosynthesis genes (ASA1/2, ASB1, TSA1, TSB1, and $A A O 1$ ) was highest at $10 \mathrm{~d}$ of moist chilling, then declined at the later stages of moist chilling $(21 \mathrm{~d})$. Interestingly, $A M I 1$, another auxin biosynthesis gene in a parallel pathway with $A A O 1$, exhibited lowest expression at $10 \mathrm{~d}$ of moist chilling (Fig. 4c). This suggests that auxin was actively synthesized during moist-chilling and mediators of the two pathways that synthesize auxin were separately activated at early and late moist-chilling. Likewise, ASA1/2, ASB1, TSA1, TSB1, and AAO1 exhibited high expression levels at 6 and $80 \mathrm{~h}$, while $A M I 1$ had a constant low expression level during germination. In Arabidopsis, there exists a third auxin biosynthesis pathway via YUC [57]; no homolog to the Arabidopsis YUC gene was found in white spruce after an extensive database search, and this auxin biosynthesis route may not exist in the seeds of this conifer species. The expression of IAR3 and $I L L 1 / 2$, which specify enzymes that convert conjugated IAA to active IAA, as well as expression of genes for the auxin transporters PIN1-like and CUC-like was significantly up- and then down- regulated in association with the transcript regulation of the biosynthesis genes of the AAO1 pathway during moist chilling (Fig. 4c). In seeds placed under standard germination conditions, the genes for the auxin transporters exhibited a pattern of heightened transcript abundance during germination, and lowered expression during seedling growth (Fig. 4c).

Auxin signalling primarily depends on the TIR1/AFB auxin receptor (TAAR), Aux/IAA, and ARF4. The expression of TIR1, AFB3 and $A u x / I A A$ was significantly up and then down regulated during moist-chilling and that of ARF4 appeared to follow the same pattern but at a lower absolute level (Fig. 4c). At $6 \mathrm{~h}$ in germination conditions, the expression of TIR1, AFB3, Aux/IAA, and $A R F 4$ significantly increased but only TIR1 and AFB3 continued to increase at $24 \mathrm{~h}$. At the seedling stage, ARF4 along with TIR1, AFB3, and $A u x / I A A$ was expressed at a fairly low level (Fig. 4c). Likewise, transcript for CUL1, a component of SCF ubiquitin ligase complexes, was substantially produced during $80 \mathrm{~h}$ in germination but not during seedling growth (Fig. 4c).

\section{Dynamic changes of hormone signalling pathways after dormancy termination during germination and radicle protrusion}

To separate the contributions of optimal germination temperature and light signalling to germination completion (i.e. radicle protrusion), two additional germination conditions in place of the standard conditions were used after seeds had received 21 days of moist chilling. As controls, seeds were not exposed to light (i.e. kept in darkness) but were exposed to either an optimal germination temperature $\left(30 / 20^{\circ} \mathrm{C}\right)$ (Fig. 1a) or a non-optimal germination temperature (constant $20^{\circ} \mathrm{C}$ ) (not shown in Fig. 1a). Transferring seeds to standard (i.e. optimal) germination conditions led to greater fold transcript changes than transferring seeds to the same temperature regime but keeping them in darkness. Transferring seeds to $20^{\circ} \mathrm{C}$ in darkness further reduced transcript induction (Figs. 2c, 3c, and 4c). This effect was particularly obvious for the studied genes of the GA pathway.

PCA analysis for all studied genes in different germination conditions was conducted (Fig. 5 and Additional file 1: Figure S4). Gene expression variations (68.96 and 

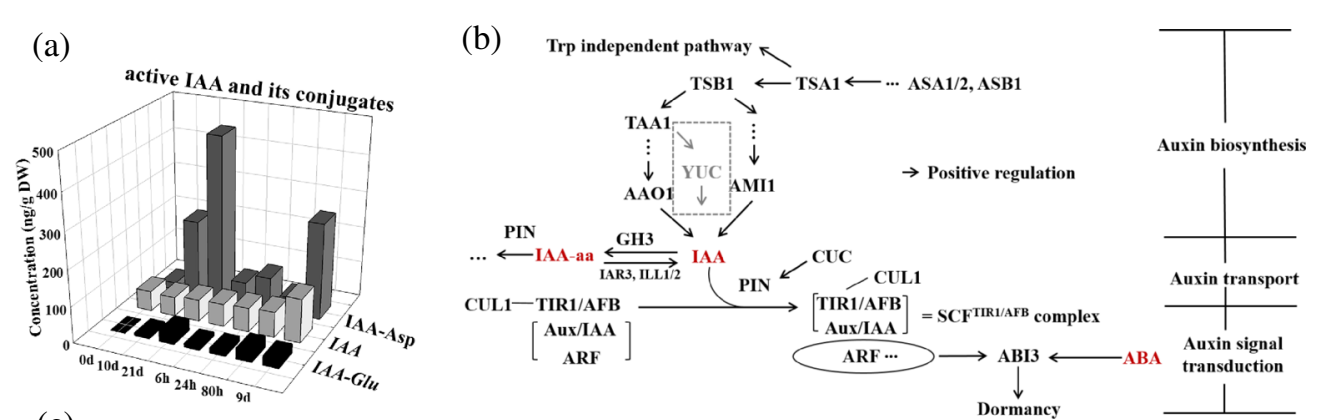

(c)
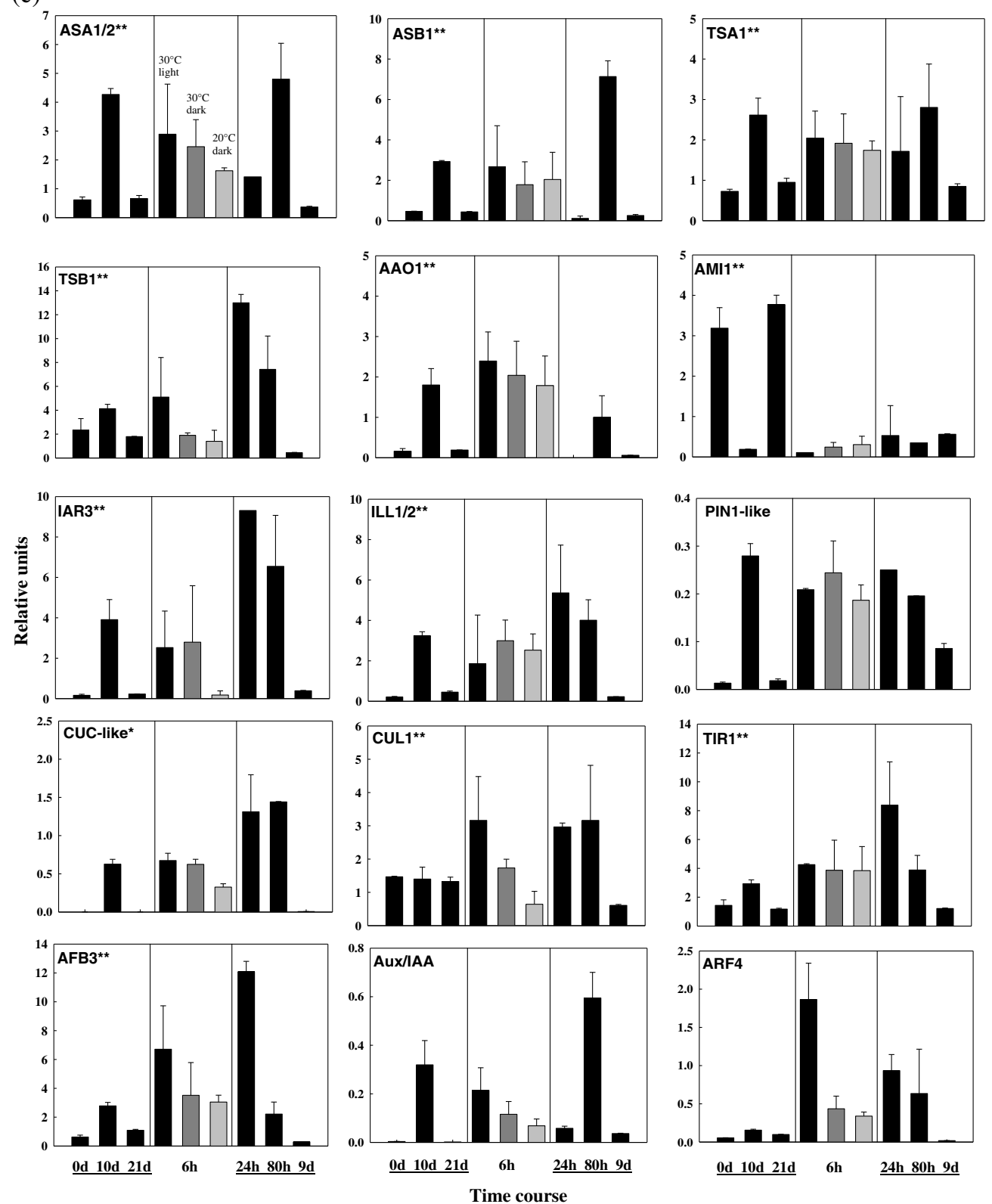

Fig. 4 (See legend on next page.) 
(See figure on previous page.)

Fig. 4 Changes in IAA, IAA conjugates, and auxin-related gene expression during the transition from dormancy to germination of white spruce seeds. a IAA and IAA conjugates in seeds as determined by UPLC/ESI-MS/MS during moist-chilling at $3{ }^{\circ} \mathrm{C}(0,10$, and $21 \mathrm{~d})$ and during germination $(6$, 24 and $80 \mathrm{~h}$ ) and seedling growth (9 d). Each data point is the average of two biological replicates. $\mathbf{b}$ Schematic characterization of key genes and their interplays in auxin signalling cascade. Connections represent positive (arrow) regulation. c Transcript levels of auxin metabolism genes, auxin signalling genes and selected downstream targets during moist-chilling (0, 10,21 d), germination (6, 24, $80 \mathrm{~h}$ ) and seedling growth (9 d) (black bars). Also shown are previously chilled seeds placed in two control treatments $-6 \mathrm{~h}$ germination conditions under darkness at either $30^{\circ} \mathrm{C}$ (dark grey bar) or $20^{\circ} \mathrm{C}$ (light grey bar). Each data point is the average of three biological replicates. Bars indicate the SEM. Notes: 1) see Fig. 2 note for asterisk in c; 2) no other ARF homologs (such as ARF16) and GH3 (converting active IAA to IAA-aa) homologs were found in white spruce by BLASTN

$27.08 \%)$ were explained by PC1 and PC2, respectively, and the PCA grouped the samples into five clusters (Fig. 5). Based on PCA analysis, we found that: 1) germination initiation $(6 \mathrm{~h})$ and radicle protrusion $(80 \mathrm{~h})$ under standard germination conditions $\left(30 / 20{ }^{\circ} \mathrm{C}\right.$ and 8 $\mathrm{h}$ photoperiod) were associated with similar gene expression patterns. The same was true of $6 \mathrm{~h}$ and $24 \mathrm{~h}$ in darkness with a $30 / 20{ }^{\circ} \mathrm{C}$ temperature cycle and of 24 and $80 \mathrm{~h}$ in constant low temperature $\left(3^{\circ} \mathrm{C}\right)$ with an 8 -h photoperiod; 2) gene expression patterns at $80 \mathrm{~h}$ in constant darkness were similar to those at $24 \mathrm{~h}$ with an 8 -h photoperiod; 3) six h in low temperature was associated with unique gene expression patterns. Therefore, seeds in constant darkness with temperature cycles displayed a similar expression pattern but were delayed in time, compared with those seeds placed under both optimal germination temperature and photoperiod cycles, Conversely, seeds in constant low temperature with an 8-h photoperiod exhibited different gene expression patterns at $6 \mathrm{~h}$, and at 24 and $80 \mathrm{~h}$, despite not completing germination (visible radicle protrusion) (Fig. 5). Taken together, temperature and light jointly promoted germination mediated by ABA, GA, and auxin pathways.

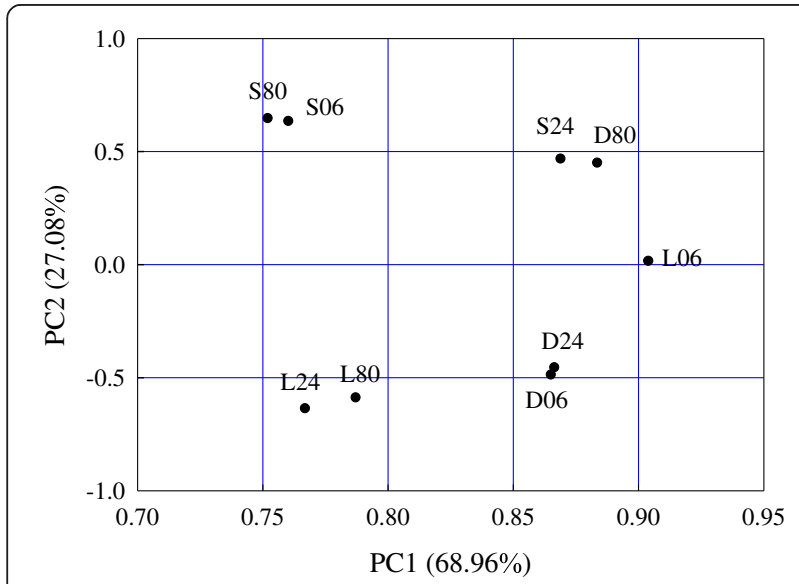

Fig. 5 The results of principle component analysis applied to the expression of all the genes used in previous qPCR analysis in ABA and GA pathways over three different germination conditions. S06/S24/S80, D06/D24/D80, and L06/L24/L80 represent standard, darkness, and low temperature $\left(3^{\circ} \mathrm{C}\right)$ germination conditions corresponding to $D / E / F$, $\mathrm{H} / \mathrm{I} / \mathrm{J}$, and $\mathrm{K} / \mathrm{L} / \mathrm{M}$ in Fig. 1a, respectively

\section{Discussion}

\section{Plant hormones co-ordinately respond to temperature} cues

Moist-chilling is associated with changes in hormone flux

IAA biosynthesis was active during moist-chilling (Fig. 4c), but active IAA levels were maintained at constant levels, while conjugated IAA-Asp and IAA-Glu steadily and significantly increased (Fig. 4a). Conjugated IAAs are regarded as storage compounds, which, in seeds, are either stored to be activated by de-conjugation and serve in early seedling growth, or are used for an entry route into subsequent catabolism [58]. IAA conjugated to amino acids such as aspartate and glutamate may be largely degraded [59]. Although the function of IAA conjugates and the genes that regulate their formation is scarcely investigated, the large amount of IAA conjugates that accumulated during moist-chilling likely has biological significance. More information is required concerning the cellular distribution of the different auxin forms as well as their relative dependence on specific transport mechanisms [60].

The PIN family proteins and the recently discovered PIN-LIKES are important as IAA efflux carriers in IAA transport between the cytosol and the endoplasmic reticulum [60, 61]. We observed that, at $10 \mathrm{~d}$ of moistchilling, and during subsequent germination, transcripts of PIN1-like and CUC-like were markedly up-regulated (Fig. 4c) while active IAA remained relatively constant (Fig. 4a). Auxin-induced cell expansion connected to the acidification of the cell wall, is thought to invoke an increase in the activity of the wall loosening proteins, expansins [62], which can disrupt the non-covalent bonds that form between cellulose and hemicellulose in the wall and thus promote cell expansion [63]. Despite no substantial overall increase in IAA during germination, IAA may nonetheless be redistributed within seed tissues to active areas of cell expansion due to the action of various transporters (Fig. 4c). Polar transport sets up auxin gradients in specific cell types, and such gradients can provide developmental cues during key processes including embryogenesis and root development [64, 65].

The auxin response not only depends on auxin levels and locations, but also on the specificity and strength of the TIR1-Aux/IAA and Aux/IAA-ARF interactions [45]. 
The decreased availability of TIR1 could lead to increased levels of free Aux/IAAs, which would combine with ARF4, thereby eventually decreasing free ARF4 levels. Hence, it is possible that prior to $10 \mathrm{~d}$ of moist chilling, Aux/IAA is predominantly combined with TIR1/AFB3 rather than with ARF4, and that the free ARF4 contributes to the increase of $A B I 3$ transcripts at $10 \mathrm{~d}$ (Figs. 4c and 2c), because ARFs may bind to putative auxin response elements (AuxREs) of the $A B I 3$ gene promoter [42]. Conversely, after $10 \mathrm{~d}$, ARF4 may be more likely to interact with Aux/IAA [45], thus lowering free ARF4 and contributing to the decreasing expression of $A B I 3$ at $21 \mathrm{~d}$ (Figs. 4c and 2c). These changing interactions between components of the $\mathrm{ABA}$ and auxin signalling pathways may promote dormancy alleviation [42]. Our analyses were confined to monitoring transcript levels and so we can only speculate as to changes at the level of the proteins that mediate auxin and ABA action. Changes in transcript levels for the ABI3 antagonist - CnAIP2 - may also be relevant here as the CnAIP2 promoter is exquisitely regulated by auxin.

Active ABA did not decrease during moist-chilling itself, but did decrease substantially during subsequent germination (Fig. 2a), at a time when $\mathrm{GA}_{53}$ of the early 13-hydroxylation pathway conducive to the formation of bioactive $\mathrm{GA}_{1}$, increased steadily (Fig. 3a and c). Thus an increased GA/ABA ratio, was clearly associated with germination of white spruce seeds [66]. We did not detect any bioactive cytokinin in our samples (Additional file 1: Figure S1). Cytokinin and auxin have long been known to interact antagonistically, and the past five years have seen significant advances in our understanding of the extensive crosstalk between cytokinin and various other hormones, particularly auxin (reviewed in [67]). In our study, none of bioactive free base cytokinins (zeatin, dihydrozeatin, and isopentenyladenine) was detected during moist chilling. However, the biosynthesis precursors cis-zeatin roboside (cis-ZR) and isopentenyladenine riboside (iPR) were markedly increased, while the catabolism product cis-zeatin-Oglucoside (cis-ZOG) was detected only at very low levels during moist-chilling (Additional file 1: Figure S1). This may indicate that a small amount of cis-zeatin was transiently produced as a result of moist chilling.

SPT (SPATULA) is thought to be involved in both ABA and GA signaling cross talk and may drive two antagonist roles in mature seeds of Arabidopsis - 'dormancy-promoting' and 'dormancy-repressing' - depending on the ecotype background $[68,69]$. In white spruce seeds, SPT expression decreased to a low level at $10 \mathrm{~d}$ of moist chilling but exhibited a 14-fold increase at $21 \mathrm{~d}$ (Fig. 3c). Its role in white spruce dormancy alleviation and germination remains to be determined.

\section{Germination conditions}

When seeds were transferred to germination conditions, we observed remarkably strong changes in expression of our monitored genes typically by only $6 \mathrm{~h}$. Transcripts encoding the GA-regulated cell wall-modifying protein expansin 2 (EXP2) were 15-fold up-regulated, indicating a strong up-regulation in GA signalling (Fig. 3c). ABA declined especially after $24 \mathrm{~h}$ (Fig. 2a). ABI3 was expressed at low levels at $6 \mathrm{~h}$ but was up regulated at $24 \mathrm{~h}$, perhaps relevant to a 'stress sensing' function at this critical stage (Fig. 2c). At the radicle protrusion time-point $(80 \mathrm{~h})$, transcripts of genes specifying auxin biosynthesis enzymes (ASA1/2, ASB1, TSA1, and AAO1), or proteins mediating conversion to active IAA (IAR3 and $I L L 1 / 2)$, and signaling $(A u x / I A A)$ were substantially produced, and these pathways may have acted in concert with those of the GA and ABA signaling pathways (Fig. 4c). Thus auxin likely also plays a pivotal role in germination of white spruce seeds.

Plants have evolved a battery of photoreceptors to sense ambient light and transduction of light signals [70]. In the control of seed dormancy and germination, phytochromes represent the most investigated photoreceptors. Phytochromes are temperature- and lightdependent in association with the GA pathway via SPT [71]. The expression of SPT significantly decreased at $6 \mathrm{~h}$ and the transcript levels were almost the same as those in the seeds exposed to light or kept in darkness. However, the seeds placed in $30^{\circ} \mathrm{C}$ had a lower level of $S P T$ transcripts than seeds placed in $20{ }^{\circ} \mathrm{C}$ (Fig. 3c). In white spruce, as in Arabidopsis, SPT may be a lightstable repressor of seed germination and may play a role in the germination response to temperature through temperature-sensitive changes in its transcription [68].

\section{Winter chilling under new climate scenarios and its effects on conifer life histories}

Winter chilling is an important signal for regulating plant life histories; chilling leads to a competence for flowering through vernalization in winter annuals, and alleviates both bud and seed dormancy, allowing the onset of growth in the spring [9, 72]. It is noteworthy that climate change may ultimately result in winter shortening and an increase in the growing season length [73, 74]. In North America, the number of winter chilling days has become insufficient for bud dormancy break from $40^{\circ} \mathrm{N}$ southward as climate changes, leading to delayed vegetation green-up, but it has remained sufficient from $40^{\circ} \mathrm{N}$ northwards as earlier springs lead to an advanced green-up onset [75]. A similar geographic pattern as observed in budburst may also occur for germination in temperate regions and two possible scenarios exist depending on whether moist-chilling requirements are minimally met; namely, fast and prompt germination 
leading to greater recruitment (adequate chilling) or an extended germination span leading to adverse conditions during dry summers (inadequate chilling) (see Fig. 1b). Thus shorter winters may delay or advance germination [76].

On the other hand, the range of spruce trees and other conifers cover large climatic gradients while their subpopulation can be adapted to their local environments [77, 78]. These populations may draw on alternative molecular solutions to respond to local environmental conditions $[79,80]$. Presumably, variations in gene expression contribute to phenotypic diversity including dormancy variation and, therefore sustain the adaptability of conifer populations [81]. As such, our results of gene expression during moist-chilling may help predict future seed recruitments in response to climate change. Finally, it is important to note that the seeds of certain other conifer species (yellow cypress, western white pine and white bark pine) exhibit much deeper dormancy at maturity than white spruce seeds. These seeds require several months of moist chilling to alleviate their dormancy, and may well be more substantially impacted by climate change, as the extended cold period is so critical for their ability to germinate.

\section{Conclusions}

In addition to classic ABA and GA mechanisms, auxin appears to be actively involved in dormancy termination and germination of white spruce seeds. We hypothesize that auxin signalling plays a role in these processes partly by interacting with ABA signalling. This is in accordance with recent findings regarding the crosstalk of auxin and ABA in the regulation of seed dormancy in angiosperms [42]. Auxin has a dominant role in plant morphogenesis and is an inescapable player in many developmental processes and a central component of crosstalk networks. Our findings now point to auxin as a key player that likely works in conjunction with the $\mathrm{ABA}$ and GA signal pathways previously investigated in mechanisms underlying dormancy alleviation by chilling in conifer seeds. Our study also yields insights into the speed with which imbibed seeds can adjust their transcription to environmental conditions, as demonstrated when seeds were transferred from moist chilling to germination conditions. After only six hours in light at higher temperatures, significant changes in transcript abundance were observed.

\section{Additional file}

Additional file 1: Table S1. Description of genes and primer pairs used for QPCR. Figure S1. Profiles of cytokinins and their metabolites in seeds of white spruce (as determined by UPLC/ESI-MS/MS) during moist-chilling at $3^{\circ} \mathrm{C}(0,10$, and $21 \mathrm{~d})$, and during germination $(6,24$ and $80 \mathrm{~h})$ and seedling growth ( $9 \mathrm{~d}$ ). Each data point is the average of two biological replicates. cis-ZR, cis-Zeatin riboside; iPR, Isopentenyladenine roboside; cis-ZOG, cis-Zeatin-O-glucoside. Figure S2. Transcript levels of various marker genes at 6 , 24 , and $80 \mathrm{~h}$ following transfer of seeds to standard germination conditions (i.e. 8-h photoperiod and $30 / 20^{\circ} \mathrm{C}$ ) (black bars), constant darkness with a $30 / 20^{\circ} \mathrm{C}$ cycle (light grey bars), or constant $3{ }^{\circ} \mathrm{C}$ with an 8 -h photoperiod (dark grey bars). Each data point is the average of three biological replicates. Bars indicate the SEM. Figure S3. C(t) values for all three reference genes across studied time-points. Figure S4. Repeatability of hormone quantification analyses. Note: variation between two experimental replicates in four metabolites (IAA-Asp, IAA, PA, and ABA) was distinguished by colours in the panel. (DOCX $475 \mathrm{~kb})$

\section{Abbreviations}

ABA: Abscisic acid; ABA-GE: abscisic acid glucose ester; PA: Phaseic acid; DPA: Dihydrophaseic acid; neo-PA: neo-phaseic acid; 7'OH-ABA: 7'-hydroxy abscisic acid; GA: Gibberellin; GA 53/34: Gibberellin 53 and 34; IAA: Indole-3-acetic acid; IAA-Asp: N-(Indole-3-yl-acetyl)-aspartic acid; IAA-Glu: N-(Indole-3-yl-acetyl)glutamic acid; AAO3: Abscisic acid aldehyde oxidase 3; CYP707As: Aba 8'hydroxylases; PYR/RCAR: Pyrbactin resistance 1-like/ regulatory component of aba receptor; PP2C: Protein phosphatase 2C; SnRK2: Sucrose nonfermenting 1 (SNF1)- Related protein kinase 2; ABI3/5: Aba insensitive 3/5; AIP2: ABI3-interacting protein 2; LEC1: Leafy cotyledon 1; ABF/AREB: Abscisic acid responsive elementbinding factor; CPS: Ent-copalyl diphosphate synthase; KS: Ent- kaurene synthase; GA20ox: Gibberellin 20 oxidase; GA3ox: Gibberellin 3 oxidase; GA2ox: Gibberellin 2 Oxidase; GID1: Gibberellin insensitive dwarf 1; BME3: Blue micropylar end 3; SPY: Spindly; EXP2: Expansin A2; SPT: Spatula; ASA1/2: Anthranilate synthase component I-1/2; ASB1: Anthranilate synthase beta subunit 1; TSA1: Tryptophan synthase alpha chain 1; TSB1: Tryptophan synthase beta subunit 1; AAO1: Aldehyde oxidase 1; AMI1: Amidase 1; IAR3: IAA-alanine resistant 3 (IAA-amino acid hydrolase); ILL1/2: IAA-leucine resistant (ILR)-like 1/2 (IAA-amino acid hydrolase); PIN1-like: Pin formed 1-like; CUC-like: Cup-shaped cotyledon-like; CUL1: Cullin1; TIR1: Transport inhibitor response 1; AFB3: Auxin signaling F-box 3; Auxin/ IAA: Auxin-induced protein 2 (AUXIN/IAA); ARF4: Auxin responsive factor 4.

\section{Competing interests}

The authors declare that they have no competing interests.

\section{Authors' contributions}

Conceived and designed the experiments: YL ARK KM YAK. Performed the experiments: YL. Analyzed the data: YL. Wrote the paper: YL ARK KM YAK. All authors have read and approved the final version of the manuscript.

\section{Acknowledgements}

We would like to extend our thanks to Dr. T-P. Sun (Duke University) for the KS antibody, to Dr. L. Irina Zaharia (Plant Biotechnology Institute) for the hormone quantification data, and to Mr. D. Kolotelo (British Columbia Ministry of Forests, Land and Natural Resource Operations) for seed supply. We gratefully acknowledge funding by the European Commission to KM through a Marie Curie IOF Fellowship, and from NSERC Discovery grants to ARK and YEK.

\section{Author details}

${ }^{1}$ Department of Forest and Conservation Sciences, Faculty of Forestry, University of British Columbia, Vancouver, British Columbia V6T 1Z4, Canada. ${ }^{2}$ Department of Biological Sciences, Simon Fraser University, Burnaby, British Columbia V5A 1S6, Canada.

Received: 26 August 2015 Accepted: 5 October 2015

Published online: 18 December 2015

\section{References}

1. Bousquet J, Isabel N, Pelgas B, Cottrell J, Rungis D, Ritland K. Spruce. Forest Trees. 2007;7:93-114.

2. Nystedt B, Street NR, Wetterbom A, Zuccolo A, Lin YC, Scofield DG, et al. The Norway spruce genome sequence and conifer genome evolution. Nature. 2013;497(7451):579-84.

3. Birol I, Raymond A, Jackman SD, Pleasance S, Coope R, Taylor GA, et al. Assembling the $20 \mathrm{~Gb}$ white spruce (Picea glauca) genome from wholegenome shotgun sequencing data. Bioinformatics. 2013;29(12):1492-7. 
4. Rigault P, Boyle B, Lepage P, Cooke JEK, Bousquet J, MacKay JJ. A white spruce gene catalog for conifer genome analyses. Plant Physiol. 2011;157(1):14-28.

5. Baskin CC, Baskin MJ. Seeds: ecology, biogeography, and evolution of dormancy and germination. San Diego: Academic; 1998.

6. Bewley JD, Bradford KJ, Hilhorst HWM, Nonogaki H: Seeds: Physiology of development, germination, and dormancy. 3rd ed. In. eBook: Springer; 2012

7. Batlla D, Benech-Arnold RL. Predicting changes in dormancy level in natural seed soil banks. Plant Mol Biol. 2010;73(1-2):3-13.

8. Finch-Savage WE, Cadman CSC, Toorop PE, Lynn JR, Hilhorst HWM. Seed dormancy release in Arabidopsis Cvi by dry after-ripening, low temperature, nitrate and light shows common quantitative patterns of gene expression directed by environmentally specific sensing. Plant J. 2007:51(4):738-8.

9. Penfield S, Springthorpe V. Understanding chilling responses in Arabidopsis seeds and their contribution to life history. Philos Trans R Soc Lond B Biol Sci. 2012;367(1586):291-7.

10. Graeber K, Nakabayashi K, Miatton E, Leubner-Metzger G, Soppe WJ. Molecular mechanisms of seed dormancy. Plant Cell Environ. 2012;35(10):1769-86.

11. Finkelstein R, Reeves W, Ariizumi T, Steber C. Molecular aspects of seed dormancy. Annu Rev Plant Biol. 2008;59:387-415.

12. Kucera B, Cohn MA, Leubner-Metzger G. Plant hormone interactions during seed dormancy release and germination. Seed Sci Res. 2005;15(4):281-307.

13. Anderson JV, Dogramaci M, Horvath DP, Foley ME, Chao WS, Suttle JC, et al. Auxin and ABA act as central regulators of developmental networks associated with paradormancy in Canada thistle (Cirsium arvense). Funct Integr Genomics. 2012;12(3):515-31.

14. Linkies A, Leubner-Metzger $\mathrm{G}$. Beyond gibberellins and abscisic acid: how ethylene and jasmonates control seed germination. Plant Cell Rep. 2012;31(2):253-70

15. Schneider H, Schuettpelz E, Pryer KM, Cranfill R, Magallon S, Lupia R. Ferns diversified in the shadow of angiosperms. Nature. 2004;428(6982):553-7.

16. Forbis TA, Floyd SK, de Queiroz A. The evolution of embryo size in angiosperms and other seed plants: Implications for the evolution of seed dormancy. Evolution. 2002;56(11):2112-25.

17. Linkies A, Graeber K, Knight C, Leubner-Metzger G. The evolution of seeds. New Phytol. 2010;186(4):817-31.

18. Hauser F, Waadt R, Schroeder JI. Evolution of abscisic acid synthesis and signaling mechanisms. Curr Biol. 2011;21(9):R346-55.

19. Yamauchi Y, Ogawa M, Kuwahara A, Hanada A, Kamiya Y, Yamaguchi S. Activation of Gibberellin biosynthesis and response pathways by low temperature during imbibition of Arabidopsis thaliana seeds. Plant Cell. 2004;16(2):367-78

20. Ali-Rachedi S, Bouinot D, Wagner MH, Bonnet M, Sotta B, Grappin P, et al. Changes in endogenous abscisic acid levels during dormancy release and maintenance of mature seeds: studies with the Cape Verde Islands ecotype, the dormant model of Arabidopsis thaliana. Planta. 2004;219(3):479-88.

21. Ogawa M, Hanada A, Yamauchi Y, Kuwalhara A, Kamiya Y, Yamaguchi S. Gibberellin biosynthesis and response during Arabidopsis seed germination. Plant Cell. 2003;15(7):1591-604.

22. Schmitz N, Abrams SR, Kermode AR. Changes in ABA turnover and sensitivity that accompany dormancy termination of yellow-cedar (Chamaecyparis nootkatensis) seeds. J Exp Bot. 2002;53(366):89-101.

23. Corbineau F, Bianco J, Garello G, Come D. Breakage of Pseudotsuga menziesii seed dormancy by cold treatment as related to changes in seed ABA sensitivity and ABA levels. Physiol Plant. 2002;114(2):313-9.

24. Feurtado JA, Ambrose SJ, Cutler AJ, Ross ARS, Abrams SR, Kermode AR. Dormancy termination of western white pine (Pinus monticola Dougl. Ex D. Don) seeds is associated with changes in abscisic acid metabolism. Planta. 2004;218(4):630-9

25. Feurtado JA, Yang J, Ambrose SJ, Cutler AJ, Abrams SR, Kermode AR. Disrupting abscisic acid homeostasis in western white pine (Pinus monticola Dougl. Ex D. Don) seeds induces dormancy termination and changes in abscisic acid catabolites. J Plant Growth Regul. 2007;26(1):46-54.

26. Williams P, Bradbeer J, Gaskin P, MacMillan J. Studies in seed dormancy VIII. The Identification and Determination of Gibberellins $A_{1}$ and $A_{9}$ in Seeds of Corylus avellana L. Planta. 1974;117(2):101-8.

27. Holdsworth MJ, Bentsink L, Soppe WJJ. Molecular networks regulating Arabidopsis seed maturation, after-ripening, dormancy and germination. New Phytol. 2008;179(1):33-54.
28. Nambara E, Okamoto M, Tatematsu K, Yano R, Seo M, Kamiya Y. Abscisic acid and the control of seed dormancy and germination. Seed Sci Res. 2010;20(2):55-67.

29. Romanel EAC, Schrago CG, Counago RM, Russo CAM, Alves-Ferreira M. Evolution of the B3 DNA binding superfamily: new insights into REM family gene diversification. PLoS ONE. 2009;4(6):e5791.

30. Zeng Y, Raimondi N, Kermode AR. Role of an ABI3 homologue in dormancy maintenance of yellow cedar seeds and in the activation of storage protein and Em gene promoters. Plant Mol Biol. 2003;51(1):39-49.

31. Zeng Y, Zhao T, Kermode AR. A conifer ABI3-interacting protein plays important roles during key transitions of the plant life cycle. Plant Physiol. 2013;161(1):179-95.

32. Zhang XR, Garreton V, Chua NH. The AIP2 E3 ligase acts as a novel negative regulator of $A B A$ signaling by promoting $A B I 3$ degradation. Gene Dev. 2005;19(13):1532-43.

33. Sun TP. Gibberellin metabolism, perception and signaling pathways in Arabidopsis. Arabidopsis Book. 2008;6:e0103.

34. Seo M, Nambara E, Choi G, Yamaguchi S. Interaction of light and hormone signals in germinating seeds. Plant Mol Biol. 2009;69(4):463-72.

35. Bialek K, Cohen JD. Free and conjugated indole-3-acetic Acid in developing bean seeds. Plant Physiol. 1989;91(2):775-9.

36. Ljung K, Hull AK, Kowalczyk M, Marchant A, Celenza J, Cohen JD, et al. Biosynthesis, conjugation, catabolism and homeostasis of indole-3-acetic acid in Arabidopsis thaliana. Plant Mol Biol. 2002;49(3-4):249-72.

37. Bialek K, Michalczuk L, Cohen JD. Auxin biosynthesis during seed germination in Phaseolus vulgaris. Plant Physiol. 1992;100(1):509-17.

38. Rampey RA, LeClere S, Kowalczyk M, Ljung K, Sandberg G, Bartel B. A family of auxin-conjugate hydrolases that contributes to free indole-3-acetic acid levels during Arabidopsis germination. Plant Physiol. 2004;135(2):978-88.

39. Brady SM, Sarkar SF, Bonetta D, MCCourt P. The ABSCISIC ACID INSENSITIVE 3 $(A B / 3)$ gene is modulated by farnesylation and is involved in auxin signaling and lateral root development in Arabidopsis. Plant J. 2003:34(1):67-75.

40. Liu PP, Montgomery TA, Fahlgren N, Kasschau KD, Nonogaki H, Carrington JC. Repression of AUXIN RESPONSE FACTOR10 by microRNA160 is critical for seed germination and post-germination stages. Plant J. 2007;52(1):133-46.

41. Ramaih S, Guedira M, Paulsen GM. Relationship of indoleacetic acid and tryptophan to dormancy and preharvest sprouting of wheat. Funct Plant Biol. 2003;30(9):939-45.

42. Liu XD, Zhang $H$, Zhao $Y$, Feng $Z Y$, Li Q, Yang HQ, et al. Auxin controls seed dormancy through stimulation of abscisic acid signaling by inducing ARF-mediated ABI3 activation in Arabidopsis. P Natl Acad Sci USA. 2013;110(38):15485-90.

43. Vanneste S, Friml J. Auxin: A trigger for change in plant development. Cell. 2009;136(6):1005-16.

44. Chapman EJ, Estelle M. Mechanism of auxin-regulated gene expression in plants. Annu Rev Genet. 2009;43:265-85.

45. Calderón Villalobos LI, Lee S, De Oliveira C, Ivetac A, Brandt W, Armitage L, et al. A combinatorial TIR1/AFB-Aux/IAA co-receptor system for differential sensing of auxin. Nat Chem Biol. 2012;8(5):477-85.

46. Liu Y, Kermode AR, El-Kassaby YA. The role of moist-chilling and thermopriming on the germination characteristics of white spruce (Picea glauca) seed. Seed Sci Technol. 2013;41:321-35.

47. ISTA. International rules for seed testing. Seed Sci Technol. 1999:27:50-2.

48. Friedmann M, Ralph SG, Aeschliman D, Zhuang J, Ritland K, Ellis BE, et al. Microarray gene expression profiling of developmental transitions in Sitka spruce (Picea sitchensis) apical shoots. J Exp Bot. 2007;58(3):593-614.

49. Palovaara J, Hakman I. Conifer WOX-related homeodomain transcription factors, developmental consideration and expression dynamic of WOX2 during Picea abies somatic embryogenesis. Plant Mol Biol. 2008;66(5):533-49.

50. Rozen S, Skaletsky H. Primer3 on the WWW for general users and for biologist programmers. Methods Mol Biol. 2000;132:365-86.

51. Müller K, Bouyer D, Schnittger A, Kermode AR. Evolutionarily conserved histone methylation dynamics during seed life-cycle transitions. PLOS ONE. 2012;7(12):e51532.

52. Zhao S, Fernald RD. Comprehensive algorithm for quantitative real-time polymerase chain reaction. J Comput Biol. 2005;12(8):1047-64.

53. Chiwocha SDS, Abrams SR, Ambrose SJ, Cutler AJ, Loewen M, Ross ARS, et al. A method for profiling classes of plant hormones and their metabolites using liquid chromatography-electrospray ionization tandem mass spectrometry: an analysis of hormone regulation of thermodormancy of lettuce (Lactuca sativa L.) seeds. Plant J. 2003;35(3):405-17. 
54. Chiwocha SDS, Cutler AJ, Abrams SR, Ambrose SJ, Yang J, Ross ARS, et al. The etr1-2 mutation in Arabidopsis thaliana affects the abscisic acid, auxin, cytokinin and gibberellin metabolic pathways during maintenance of seed dormancy, moist-chilling and germination. Plant J. 2005:42(1):35-48.

55. Arc E, Chiban K, Grappin P, Jullien M, Godin B, Cueff G, et al. Cold stratification and exogenous nitrates entail similar functional proteome adjustments during Arabidopsis seed dormancy release. J Proteome Res. 2012:11(11):5418-32.

56. Williamson JD, Quatrano RS, Cuming AC. Em polypeptide and its messenger RNA levels are modulated by abscisic acid during embryogenesis in wheat. Eur J Biochem. 1985;152(2):501-7.

57. Won C, Shen XL, Mashiguchi K, Zheng ZY, Dai XH, Cheng YF, et al. Conversion of tryptophan to indole-3-acetic acid by TRYPTOPHAN AMINOTRANSFERASES OF ARABIDOPSIS and YUCCAs in Arabidopsis. P Natl Acad Sci USA. 2011;108(45):18518-23.

58. Leyser O. Dynamic integration of auxin transport and signalling. Curr Biol. 2006;16(11):R424-33.

59. Ludwig-Müller J. Auxin conjugates: their role for plant development and in the evolution of land plants. J Exp Bot. 2011;62(6):1757-73.

60. Zažímalová E, Murphy AS, Yang H, Hoyerová K, Hošek P. Auxin transporterswhy so many? Cold Spring Harb Perspect Biol. 2010;2(3):a001552.

61. Barbez E, Kubeš $M$, Rolčík J, Beziat $C$, Pěnčík $A$, Wang $B$, et al. A novel putative auxin carrier family regulates intracellular auxin homeostasis in plants. Nature. 2012;485(7396):119-22.

62. Hager A. Role of the plasma membrane $\mathrm{H}+-$ ATPase in auxin-induced elongation growth: historical and new aspects. J Plant Res. 2003;116(6):483-505.

63. Cosgrove DJ, Li LC, Cho HT, Hoffmann-Benning S, Moore RC, Blecker D. The growing world of expansins. Plant Cell Physiol. 2002;43(12):1436-44.

64. Friml J, Vieten A, Sauer M, Weijers D, Schwarz H, Hamann T, et al. Effluxdependent auxin gradients establish the apical-basal axis of Arabidopsis. Nature. 2003;426(6963):147-53.

65. Blilou I, Xu J, Wildwater M, Willemsen V, Paponov I, Friml J, et al. The PIN auxin efflux facilitator network controls growth and patterning in Arabidopsis roots. Nature. 2005;433(7021):39-44.

66. Finch-Savage WE, Leubner-Metzger G. Seed dormancy and the control of germination. New Phytol. 2006;171(3):501-23.

67. El-Showk S, Ruonala R, Helariutta Y. Crossing paths: cytokinin signalling and crosstalk. Development. 2013;140(7):1373-83.

68. Penfield S, Josse EM, Kannangara R, Gilday AD, Halliday KJ, Graham IA. Cold and light control seed germination through the bHLH transcription factor SPATULA. Curr Biol. 2005:15(22):1998-2006.

69. Vaistij FE, Gan YB, Penfield S, Gilday AD, Dave A, He ZS, et al. Differential control of seed primary dormancy in Arabidopsis ecotypes by the transcription factor SPATULA. P Natl Acad Sci USA. 2013;110(26):10866-71.

70. Moglich A, Yang X, Ayers RA, Moffat K. Structure and function of plant photoreceptors. Annu Rev Plant Biol. 2010;61:21-47.

71. Heschel MS, Selby J, Butler C, Whitelam GC, Sharrock RA, Donohue K. A new role for phytochromes in temperature-dependent germination. New Phytol. 2007;174(4):735-41.

72. Penfield S. Temperature perception and signal transduction in plants. New Phytol. 2008;179(3):615-28.

73. Robeson SM. Trends in time-varying percentiles of daily minimum and maximum temperature over North America. Geophys Res Lett. 2004;31(4):1-4

74. Schwartz MD, Ahas R, Aasa A. Onset of spring starting earlier across the Northern Hemisphere. Global Change Biol. 2006;12(2):343-51.

75. Zhang XY, Tarpley D, Sullivan JT. Diverse responses of vegetation phenology to a warming climate. Geophys Res Lett. 2007;34:L19405.

76. Walck JL, Baskin JM, Baskin CC. A comparative study of the seed germination biology of a narrow endemic and two geographicallywidespread species of Solidago (Asteraceae).1. Germination phenology and effect of cold stratification on germination. Seed Sci Res. 1997;7(1):47-58

77. Aitken SN, Yeaman S, Holliday JA, Wang TL, Curtis-McLane S. Adaptation, migration or extirpation: climate change outcomes for tree populations. Evol Appl. 2008;1(1):95-111.

78. Mimura M, Aitken SN. Local adaptation at the range peripheries of Sitka spruce. J Evolution Biol. 2010;23(2):249-58.

79. Prunier J, Laroche J, Beaulieu J, Bousquet J. Scanning the genome for gene SNPs related to climate adaptation and estimating selection at the molecular level in boreal black spruce. Mol Ecol. 2011;20(8):1702-16.
80. Prunier J, Gérardi S, Laroche J, Beaulieu J, Bousquet J. Parallel and lineagespecific molecular adaptation to climate in boreal black spruce. Mol Ecol. 2012;21(17):4270-86.

81. Verta JP, Landry CR, MacKay JJ. Are long-lived trees poised for evolutionary change? Single locus effects in the evolution of gene expression networks in spruce. Mol Ecol. 2013;22(9):2369-79.

\section{Submit your next manuscript to BioMed Central and take full advantage of:}

- Convenient online submission

- Thorough peer review

- No space constraints or color figure charges

- Immediate publication on acceptance

- Inclusion in PubMed, CAS, Scopus and Google Scholar

- Research which is freely available for redistribution 